\title{
MATHEMATICAL MODELING OF THE GRAIN MATERIAL SEPARATION IN THE PNEUMATIC SYSTEM OF THE GRAIN-CLEANING MACHINE
}

\author{
Ildar Badretdinov*, Salavat Mudarisov, Marat Tuktarov, Elizabeth Dick, Svetlana Arslanbekova \\ Bashkir State Agrarian University, Russian Federation
}

The article presents the results of a study of a high-performance grain cleaning machine for the preliminary cleaning of grain pile with a closed aspiration system. The flow regimes of the "air-grain pile" mixture determined by the Reynolds number and the bulk concentration of particles are established. As a result of the modeling, further directions for improving pneumatic systems of grain cleaning machines were determined: the cleaning efficiency of the $E_{0}$ fraction of pure grain from light impurities, shriveled and crushed grain reaches $82 \%$, the output cleanliness of the grain was $93.7 \%$, and the loss of full grain to waste $P_{z}=0,017 \%$. The average speed of the air flow in the separating channel is $U=7.12 \mathrm{~m} / \mathrm{s}$, its coefficient of variation across the width of the separating channel is $v=12,7 \%$. The results of the experimental data confirmed the adequacy of using mathematical modeling of the air flow in the pneumatic system of a grain cleaning machine to substantiate the basic parameters of the pneumatic system.

Key words: grain cleaning machine, pneumatic system, mathematical model, grain pile separation, process modeling

\section{INTRODUCTION}

\section{The problem statement}

In pneumatic systems of grain pre-cleaning machines, the process of separating a grain pile from large impurities (spikelets, straw residues, etc.) and light impurities (husks, small weed seeds, etc.) occurs by airflow [1-5]. However, modern grain cleaning machines for preliminary cleaning of grain pile with a pneumatic system as their main working element, in their operational qualities do not fully meet the increasing requirements of modern agricultural production [6-9]. Due to the imperfection of the design of the pneumatic system, there is an increased dustiness in the service areas and poor-quality separation of the grain pile by the air flow [10-12]. The development of a new technology for the separation of a heap of grain and more advanced technology for its implementation is difficult due to the diversity of crops and methods of separation; the complexity and diversity of the process of interaction of the particles of the separated materials with the air flow and the working bodies of the machine; insufficient development of the theoretical foundations of separation by air flow and methods for substantiating the parameters of machines and the modes of their operation [13-17]. In this regard, it is necessary to improve the theory of separation by air flow and the designs of pneumatic systems of grain cleaning machines [18-20].

\section{Research aims}

The accuracy of the mathematical description of the technological process of the pneumatic system of the grain cleaning machine for the preliminary cleaning of the grain pile (GCM) depends largely on how the presence and intensity of the interfacial interaction (particle relaxation time), particle concentration, etc., are taken into account in the mathematical model. It is necessary to establish the "gas-particle" interaction mode (air-grain and air-impurities), which is determined by the Reynolds number of the $\operatorname{Re}_{p}$ particle and the volume concentration of the particles $\Phi$, as well as the kinematic (structural-technological) parameter of the pneumatic system. In turn, to determine the data of these parameters, it is necessary to know the amount of the material entering the cleaning (capacity), the speed of the air flow and particles, as well as their aerodynamic drag coefficients. Thus, the purpose of this paper is to substantiate the parameters of the air flow and grain pile (particles with different physical and mechanical properties) for the implementation of the mathematical model of the technological process of the pneumatic system of the grain cleaning machine for pre-cleaning of the grain pile, taking into account its structural and technological parameters.

\section{MATERIALS AND METHODS}

A wide range of mathematical models is offered to describe gas flows with solid particles. They differ in the way they describe the motion of gas and particles, the assumptions made, and the areas of applicability. The choice of a suitable model is made taking into account the available information on the flow structure and the required accuracy of its description. The construction of mathematical models describing the flow of gas with an admixture of solid particles is hampered by the fact that the flow of the carrier phase is only the background against which a large number of macroscopic particles move. The practical impossibility of solving the equations of motion of each of these particles together with the equations of motion of the carrier phase, the action 
of a number of factors which randomize the movement of particles (the polydispersity of the impurity, the irregularity of the particle shape, turbulence) lead to the development of special mathematical and numerical models.

Modern methods of mathematical modeling of two-phase flows are classified into three main groups: continuum (Eulerian), trajectory (Lagrangian), kinetic (statistical). After analyzing all the advantages and disadvantages of each approach, in order to describe the movement of the air-grain mixture in the GCM pneumatic system, the most appropriate in our opinion is the mathematical model of gas flow with particles, described by the trajectory (Lagrangian) approach. The advantage of this approach is the possibility of describing non-equilibrium particle flows, i.e. particles have a different geometric parameter, density, mass, etc., the mutual influence of the particles themselves, the turbulence of the air flow, the mutual influence of gas and particles are also taken into account. All these features, that is, differences in the physicomechanical properties and geometrical parameters of the grains, as well as the influence of the grain mass on the nature of the separation process, are fundamental for GCM. For an accurate description and selection of a model according to the theory of two-phase flows, it is necessary to determine the class of gas (air) flow with particles (grain) in the GCM pneumatic system.

In the GCM pneumatic system, the technological process of separating a grain pile from impurities by air flow can be mathematically described as a complex system of polydisperse two-phase flow taking into account gravitational, resistance and friction forces, where one phase is air created by a fan, and the second is solid particles (grain pile). The particles have different concentrations, physical and mechanical properties (mass, density, geometrical dimensions, humidity, elasticity, sailing, etc.). The difference in the physical and mechanical properties of the phases determines the nature of the interaction of air and particles. The inertia and sailing of various particles (heavy - seeds, light - husks, impurities) lead to a different separation of the trajectories of motion from the air. In such flows, light particles move (are separated) by the air flow due to the aerodynamic drag force, which exceeds the gravitational force, the cause of which is the difference in air velocity and particle. Heavy particles mostly move (separated from the light ones) under the action of gravity, while the aerodynamic drag force acts slightly [1-18].

The force of aerodynamic drag is determined by the expression:

$\vec{F}_{A}=C_{D} \rho_{g} \frac{\pi d_{p}^{2}}{4} \frac{|\vec{U}-\vec{V}|(U-V)}{2}$

where $C_{D}$ is the aerodynamic drag coefficient of the particle, $\rho_{g}$ is the air density, $\mathrm{kg} / \mathrm{m}^{3}\left(\rho=1.225 \mathrm{~kg} / \mathrm{m}^{3}\right)$; $d_{p}$ - particle diameter, $\mathrm{m} ; U$ is the air flow speed created by the fan, $\mathrm{m} / \mathrm{s} ; \mathrm{V}$ - particle velocity, $\mathrm{m} / \mathrm{s}$.

$$
\frac{\partial U}{\partial t}+\nabla(U \otimes U)=-\frac{\nabla P}{\rho}+\frac{1}{\rho} \nabla\left(\left(\mu+\mu_{t}\right)\left(\nabla U+(\nabla U)^{T}\right)\right)+D
$$

The aerodynamic drag coefficient of spherical particles $C_{D}$ is determined according to the Rayleigh curve depending on the Reynolds number $\operatorname{Re}\left(C_{D}=f(\operatorname{Re})\right)$ [1-3]. The number of Reynolds for particles is determined by the formula

$R e_{p}=\frac{\rho_{g}|U-V| d_{p}}{\eta}$

where $\eta$ is the dynamic viscosity of air, Pa.s (at $20^{\circ} \mathrm{C}$ $\eta=1.8210^{-5} \mathrm{~Pa} \cdot \mathrm{s}$ ).

Mathematical description of the process of interaction of the air flow with a grain pile. The case is described when the forces of aerodynamic drag and gravity have the main influence on the motion of particles, the Lagrangian equations of motion will take the following form

$$
\frac{d v_{i}}{d \tau}=\frac{u_{i}-v_{i}}{\tau_{p}} \pm g
$$

Thus, we obtained the equation of the pulsation motion of inertial particles. The approach to the derivation of the pulsation equations of polydisperse particles is based on the application of the Reynolds number of particles to the Lagrangian equations.

The heterogeneous flows have their own specific characteristics: intensive and extensive. The intensive quantities include the physical properties of particles, such as their geometric parameters (equivalent diameter) $d_{p}$ and density $\rho_{p}$.

The dynamic inertia of particles is the time of exposure of a particle in the air stream, determined by their relaxation time $\tau_{p}$ (dynamic particle relaxation time), which has the following form

$$
\tau_{\mathrm{p}}=\frac{\rho_{\mathrm{p}} d_{p}^{2}}{18 \mu z}
$$

where $Z$ is the correction function

$$
Z=\left\{\begin{array}{l}
1+\frac{R e_{p}^{2 / 3}}{6} \text { with } \operatorname{Re}_{\mathrm{p}} \leq 10^{3} \\
\frac{0,11 \cdot \mathrm{Re}_{\mathrm{p}}}{6} \text { with } \operatorname{Re}_{\mathrm{p}}>10^{3}
\end{array}\right.
$$

where $\mu$ is the kinematic viscosity of air (at 200C $\mu=1,51$ -10-5 m2 / s).

The inertia of a particle depends on the characteristics of the air flow in which it moves. The correction function $Z$ takes into account the effect of inertia forces on the particle relaxation time. Thus, when a particle moves, its inertia also depends on the particle Reynolds number.

To calculate the movement of the air flow generated by a fan in a rotating coordinate system, use is made of the approximation of a one-component incompressible medium described by the Navier - Stokes equations taking into account the effects of turbulence: 
$\nabla U=0$

$D=\left(1-\frac{\rho_{\text {hyd }}}{\rho}\right) g+J+\frac{R}{\rho}$

where $P$ is the pressure; $J$ - coefficient taking into account the force of rotation, $\mu_{t}$ - turbulent viscosity.

Equations (6-8) take into account the main nonlinear mechanisms of turbulent flows: inertial forces and gravity. The rotational forces (Coriolis and centrifugal) while in the rotating coordinate system have the form:

$$
J=-2 \omega \cdot U-\omega^{2} \cdot r
$$

where $\omega$ is the angular velocity of the fan, $r$ is the radius of the fan wheel.

The equations (6-9) describe the technological process of the fan operation, taking into account the rotating wheel in the coordinate system.

The impact of the air flow generated by the fan on the grain pile entering the GCM pneumatic system, in general, based on the Navier-Stokes equation, takes the form [13-14].

$$
\frac{\partial \rho_{g}}{\partial t}+\vec{\nabla} \cdot\left(\rho_{g} U\right)=Q_{m}^{p}
$$

where $\vec{\nabla}$ is the operator nabla (Hamilton), a vector differential operator whose components are partial derivatives with respect to coordinates; $Q^{p}$ - mass feed of particles, $\mathrm{kg} / \mathrm{m}^{3} \cdot \mathrm{s}$.

The equation of motion of the elements of the grain pile

$\frac{d V_{p}}{d t}=\frac{\pi d_{p}^{2}}{8 m} C_{D} \rho_{g}|U-V p|\left(U-V_{p}\right)+g\left(1-\frac{\rho_{g}}{\rho_{p}}\right)$

The modeling the transfer of the polydisperse phase involves solving a non-uniform convective-diffusion equation for the concentration of particles:

$\frac{\partial N_{p}}{\partial t}+\nabla \cdot\left(V_{p} \cdot N_{p}\right)=\nabla \cdot\left(\frac{v_{t}}{S c_{t}} \nabla N_{p}\right)+\dot{N}_{p}$

where $v_{t}$ is the kinematic coefficient of turbulent air viscosity; $S c_{t}$ is the turbulent Schmidt number; $N_{p}$ is the concentration of particles; $\dot{N}_{p}$ - speed of ablation of light particles.

The impulse transfer of the dispersed phase is described by an inhomogeneous convective-diffusion equation that is solved for the particle velocity:

\section{Results}

Tables 1 and 2 present the main physicomechanical properties and the statistical analysis of the geometric parameters of the seeds of a grain pile.

Table 1: Statistical analysis of the geometric parameters

\begin{tabular}{|c|c|c|c|c|c|c|}
\hline & $\stackrel{\dot{\Sigma}}{\Sigma}$ & $\stackrel{\dot{x}}{\stackrel{\infty}{\Sigma}}$ & 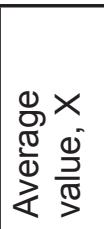 & 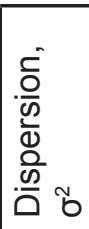 & 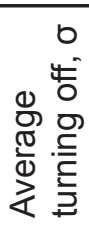 & 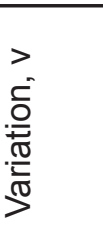 \\
\hline \multicolumn{7}{|c|}{ Grain pile (before cleaning) } \\
\hline Length $I, \mathrm{~mm}$ & 1.11 & 28.1 & 10.77 & 39.8 & 6.31 & 58.59 \\
\hline $\begin{array}{l}\text { Thickness a, } \\
\mathrm{mm}\end{array}$ & 0.3 & 9.5 & 2.11 & 1.8 & 1.34 & 63.57 \\
\hline Width $\theta, \mathrm{mm}$ & 1.4 & 5.7 & 3.53 & 1.02 & 1.01 & 28.64 \\
\hline $\begin{array}{l}\text { Equivalent } \\
\text { diameter } d_{\vartheta} \text {, } \\
\mathrm{mm}\end{array}$ & 0.72 & 5.41 & 2.59 & - & - & - \\
\hline \multicolumn{7}{|c|}{ Pure grain (after cleaning) } \\
\hline Length $I, \mathrm{~mm}$ & 5.06 & 6.92 & 6.03 & 0.22 & 0.47 & 7.74 \\
\hline $\begin{array}{l}\text { Thickness a, } \\
\mathrm{mm}\end{array}$ & 2.24 & 3.36 & 2.70 & 0.05 & 0.23 & 8.62 \\
\hline Width $\theta, \mathrm{mm}$ & 2.05 & 3.63 & 2.98 & 0.11 & 0.34 & 11.28 \\
\hline $\begin{array}{l}\text { Equivalent } \\
\text { diameter } d_{\vartheta} \text {, } \\
\mathrm{mm}\end{array}$ & 3.12 & 4.64 & 3.90 & - & - & - \\
\hline
\end{tabular}
of the grain pile and clean grain (wheat, "Vatan" variety)

Table 2: Statistical analysis of the mass of a single weevil

\begin{tabular}{|c|c|c|c|c|c|c|c|}
\hline & $\stackrel{\dot{\Sigma}}{\sum}$ & $\stackrel{\text { x }}{\sum^{\frac{\pi}{2}}}$ & 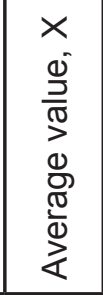 & 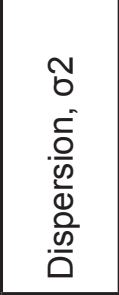 & 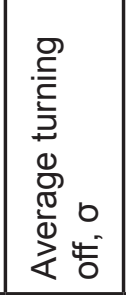 & 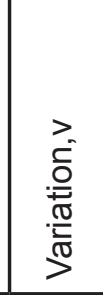 & 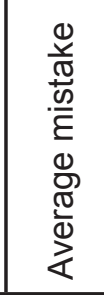 \\
\hline & 0.012 & 0.08 & 0.036 & 0.0001 & 0.0105 & 29.32 & .00 \\
\hline
\end{tabular}
(wheat, "Salavat Yulaev" variety)

$$
\begin{aligned}
& \frac{\partial\left(N_{p} V_{p}\right)}{\partial t}+\nabla \cdot\left(\left(V_{p} \cdot N_{p}-\frac{v_{t}}{S c_{t}} \nabla N_{p}\right) \otimes V_{p}\right)=-N_{p} \frac{1}{\rho_{p}} \nabla \mathrm{P}+ \\
& +\frac{1}{\rho_{g}} F_{d}+N_{p} g-\dot{N}_{p} U+F_{A} \frac{U_{p}}{\rho_{p} d^{2}}\left(U-V_{p}\right) \\
& F_{d}=-a \cdot e^{\left(-b \varphi_{p}\right) \nabla N_{p}} \\
& F_{A}=\frac{3}{4} \cdot C_{D} \cdot \rho_{g} \cdot\left|U-V_{p}\right| \cdot d_{p}
\end{aligned}
$$


As shown by experimental measurements (table 1 and 2 ), the grain pile is heterogeneous and has a wide range of both physicomechanical and geometrical parameters [13-16]. The data obtained are used in a mathematical model describing the technological process of the pneumatic system of a grain cleaning machine for pre-cleaning.

Determination of flow regime and intensity of interfacial interaction (volume and mass concentration of grain pile). The technological process of separation in the GCM pneumatic system proceeds with a relatively small volumetric content of the grain pile. At the same time, the total mass of the grain heap is several times greater than the mass of the air flow generated by the fan. In this regard, it is necessary to determine the intensity of the interfacial interaction, which is estimated by the volume and mass concentrations of the air-grain mixture.

In GCM pneumatic systems, the volume concentration of a grain pile is within $\Phi \approx 1.5 \cdot 10^{-4} \ldots 2.3 \cdot 10^{-3}$, and the mass concentration $M \approx 0.16 \ldots 2.51$, which is considered according to the accepted classification of heterogeneous flows to be slightly dusty.

In such a flow mode, the effect of the carrier phase (air flow) on the movement of solid particles (grain) is observed, and the reverse effect of particles on the air flow is negligible. As the concentration of particles (supply) increases, the effect of the grain pile on the air flow increases, as well as the interaction of the components of the pile between them. But in this case, the cleaning process is violated, which is unacceptable. Experimentally obtained concentrations are used in simulation modeling of the technological process of operation of GCM pneumatic systems in the FlowVision program.

Visualization of the trajectories of the airspeed, obtained from the results of modeling and calculation in the software package FlowVision (Figure 2-4).

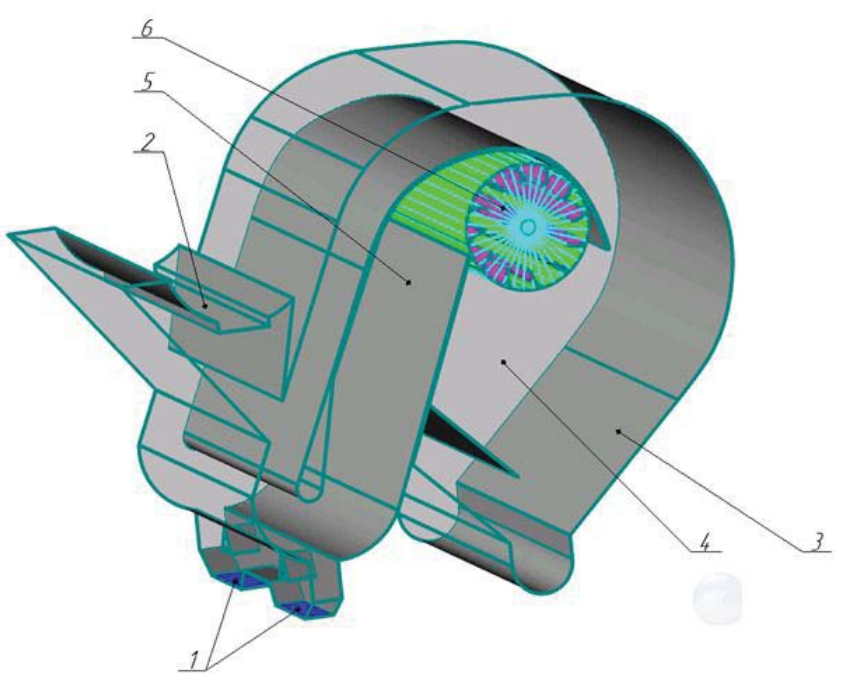

Figure 1: Model calculation area with boundary conditions: 1 - output of the purified grain; 2 - grain pile entering; 3 - wall; 4 - symmetry; 5 - air inlet; 6 - fan (rotation)

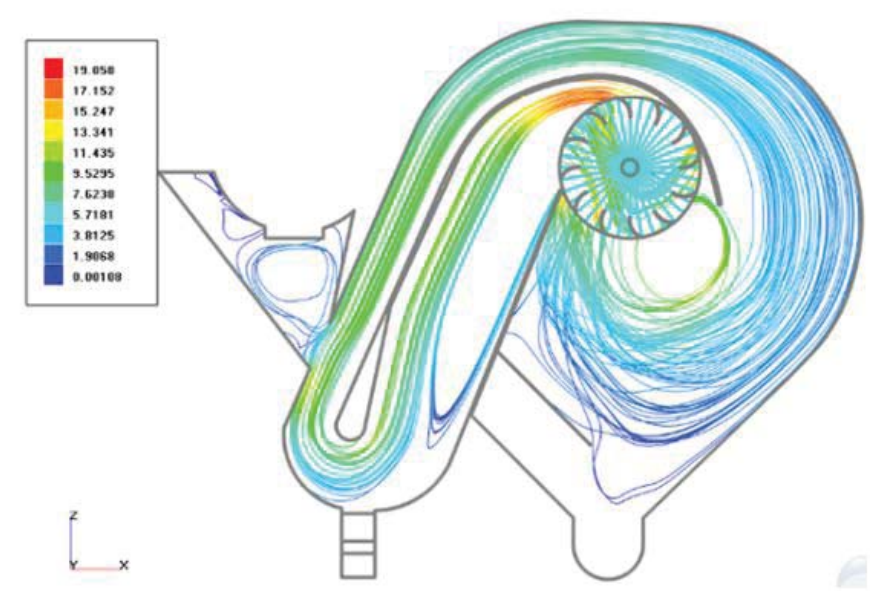

Figure 2: Trajectories of the air flow in the GCM pneumatic system

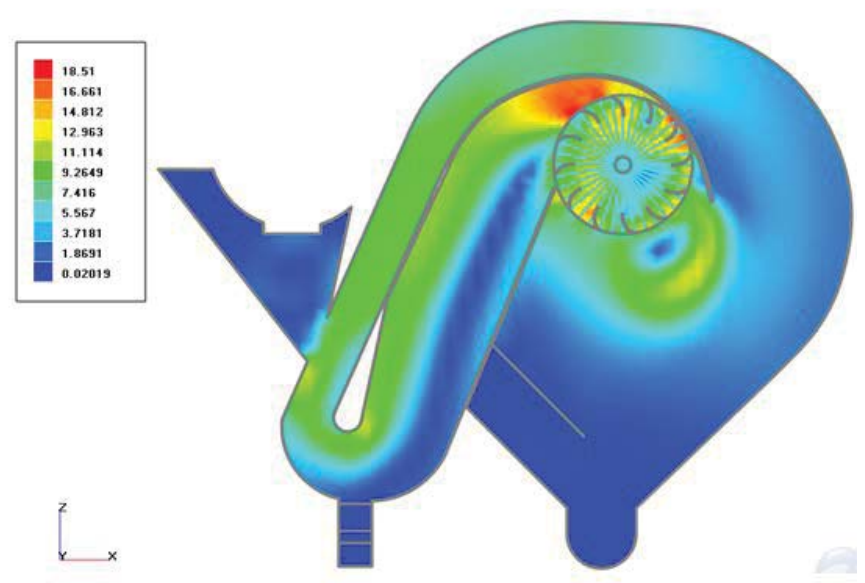

Figure 3: Distribution of the air flow rate in the GCM pneumatic system

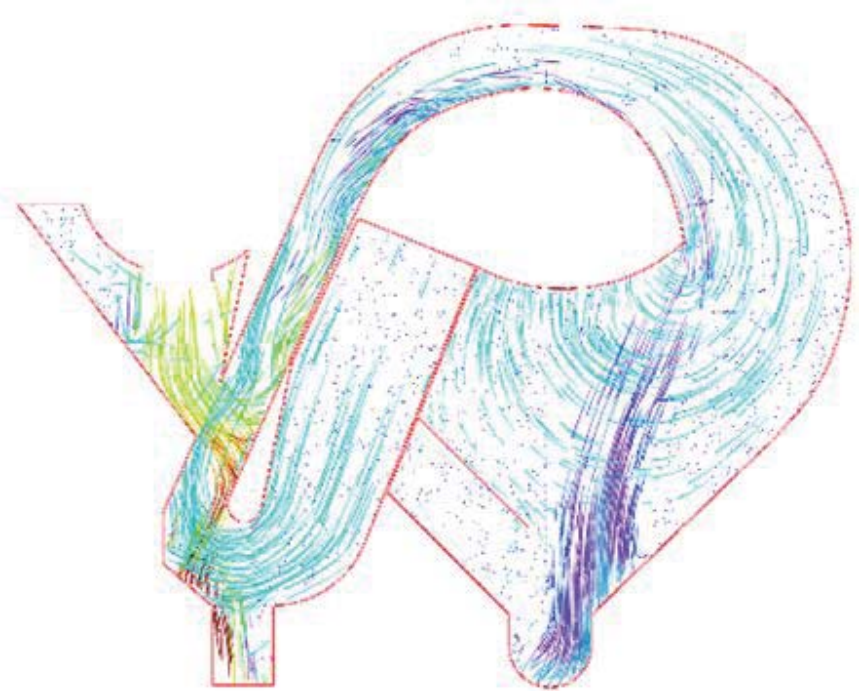

Figure 4: Visualization of the process of pneumoseparation

The effect of cleaning the $E_{0}$ fraction of pure grain from light impurities, puny and crushed grain reaches $82 \%$, and the loss of full-grain to waste $\mathrm{Lg}=0.017 \%$. The purity of the grain output was $93.7 \%$. The mass of 1,000 grains of pure grain after cleaning was $33 \mathrm{~g}$, and the nature - $754 \mathrm{~g} / \mathrm{l}$. In comparison with the existing МПО-50 


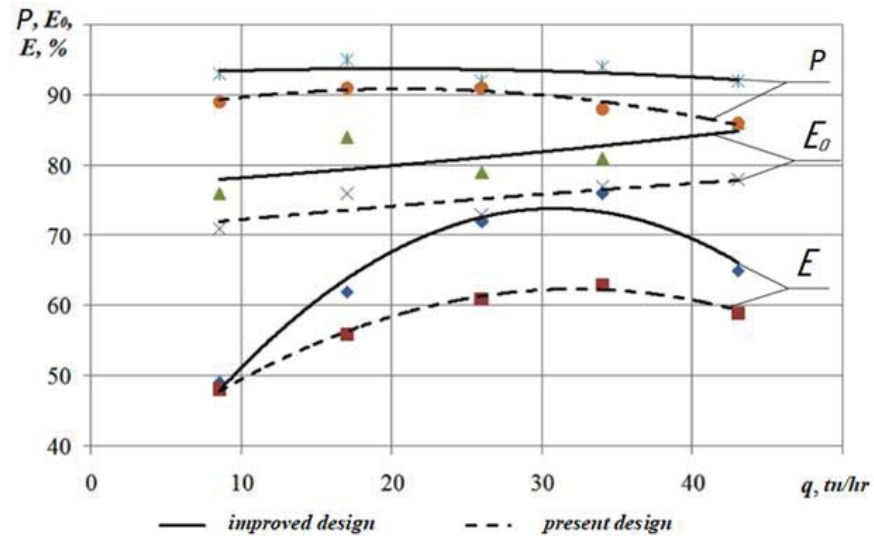

Figure 5: Graph of the $P$ purity of the fraction of pure grain, the effect of cleaning $E 0$ from light impurities, the completeness of the selection of $E$ impurities from the supply $q$ of the initial material

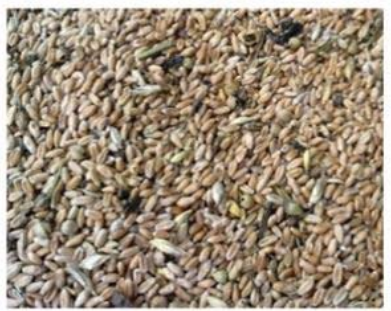

before cleaning

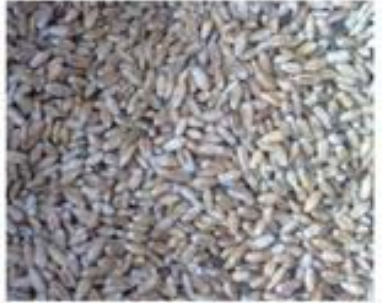

after cleaning
Figure 6: Sampling of wheat "Omskaya-36" variety

machine, the effect of cleaning the grain from light impurities $E_{0}$, the purity of the grain $\mathrm{P}$ and the completeness of the emission of impurities $E$ are 6,5 and $11 \%$ higher, respectively.

\section{DISCUSSION}

The experimental data of the distribution of air velocity in the pneumatic systems of the existing modern GCM showed that the air flow in the pneumatic separating channel is unevenly distributed and varies over a wide range (coefficient of variation $v$ to $37 \%$ ). This is evidenced by the results of other researchers [1-12]. This indicates that the technological process of separation of the grain pile in the GCM pneumatic system proceeds in violation of agrotechnical requirements. Due to the increase in productivity and throughput, there are problems of high-quality functioning of the GCM pneumatic system. This can be explained by the complexity of the simultaneous regulation of several structural and technological parameters (fan speed and air flow rate $U$, supply of grain pile q) and, depending on the crop to be harvested, on its physical and mechanical properties (geometrical parameters, humidity, impurities). The experimental data were confirmed by theoretical studies of the mathematical description and modeling in the form of a polydisperse two-phase flow with regard to concentration, inertia, relaxation time, resistance coefficient. Similar studies were carried out by other scientists, which are reflected in the works [1-13].
The adequacy of the model, theoretical and experimental studies is confirmed by their convergence (reliability is 0.97 ), which suggests that the possibility of accepting the results is reliable. By simulating and calculating a model of real pneumatic systems of existing grain cleaning machines, using this method, problem areas of the pneumatic system were identified. These problems can be solved by changing the design parameters and adding baffles to the separating channel of the pneumatic system, which contributes to a uniform distribution of the air flow across the entire width of the separating channel of the pneumatic system of the grain cleaning machine.

The obtained characteristics allow us to develop recommendations for the optimization of the structural and technological parameters of the pneumatic system of the grain cleaning machine as a whole. Using this simulation method, it is possible to improve the GCM pneumatic systems without significant costs and efforts.

\section{CONCLUSION}

The following indicators of the flow mode in the GCM pneumatic system for preliminary cleaning are substantiated: mass concentration $M=0.16 \ldots 2.51$; volume concentration of a grain pile $\Phi=1,5 \cdot 10^{-4} \ldots 2,3 \cdot 10^{-3}$; Reynolds number of grain pile $R e_{p}=125 \ldots .1884$; aerodynamic coefficient of grain pile resistance $C_{D}=0.19 \ldots 0.59$; sailing ratio coefficients - for full grains it varies in the range $k_{n}=0.09 \ldots 0.3$, and for weed admixture $k_{n}=0.4 \ldots 1.22$; dynamic inertia of grain heap particles $T_{p}=1 \ldots 28.5$. The flow mode "air - grain pile" in the GCM pneumatic system refers to heterogeneous, lightly dusty streams. The obtained parameters allow us to establish that for mathematical modeling of the technological process of operation of the pneumatic system of a grain cleaning machine, it is possible to use the methods of two-phase "gas-particle" flows as well as to develop recommendations for the optimization of the structural and technological parameters of the pneumatic system of the grain cleaning machine as a whole. Using this simulation method, it is possible to improve the GCM pneumatic systems without significant costs and efforts.

\section{REFERENCES}

1. Saitov, V.E., Kurbanov, R.F., Suvorov, A.N. (2016). Assessing the Adequacy of Mathematical Models of Light Impurity Fractionation in Sedimentary Chambers of Grain Cleaning Machines. Procedia Engineering, vol. 150, 107-110.

2. Savinyh, P., Sychugov, Y., Kazakov, V., Ivanovs, S. (2018). Development and Theoretical Studies of Grain Cleaning Machine for Fractional Technology of Flattening Forage Grain. Engineering for Rural Development, p.124-130.

3. Xu, L., Wei, C., Liang, Z., Chai, X., Li, Y., \& Liu, Q. (2019). Development of rapeseed cleaning loss monitoring system and experiments in a combine harvester. Biosystems engineering, vol. 178, 118-130. 
4. Bulgakov, V., Holovach, I., Bandura, V., Ivanovs, S. A. (2017). A theoretical research of the grain milling technological process for roller mills with two degrees of freedom. INMATEH - Agricultural Engineering, vol. 52, no. 2, 99-106.

5. Sysuev, V., Ivanovs, S., Savinyh, P., Kazakov, V. (2015). Movement and transformation of grain in two-stage crusher. Engineering for Rural Development, Proceedings, vol. 14, 22-27.

6. Giyevskiy, A. M., Orobinsky, V. I., Tarasenko, A. P., Chernyshov, A. V., Kurilov, D. O. (2018). Substantiation of basic scheme of grain cleaning machine for preparation of agricultural crops seeds. IOP Conf. Series: Materials Science and Engineering, vol. 327, DOI:10.1088/1757-899X/327/4/042035.

7. Saitov, V. E., Farafonov, V. G., Gataullin, R. G., Saitov, A.V. (2018). Research of a diametrical fan with suction channel. IOP Conf. Series: Materials Science and Engineering, vol. 457, DOl:10.1088/1757899X/457/1/012009.

8. Dal-Pastro, E., Facco, P., Bezzo, E., Zamprogna, E., Barolo, M. (2016). Data-driven modelling of milling and sieving operations in wheat milling process. Food and Bioproducts Processing, vol. 99, 99-108.

9. Mudarisov, S., Khasanov, E., Rakhimov, Z., Gabitov, I., Badretdinov, I., Farchutdinov, I., Gallyamov, F., Davletshin, M., Aipov, R., Jarullin, R. (2017). Specifying Two-Phase Flow in Modeling Pneumatic Systems Performance of Farm Machines. Journal of Mechanical Engineering Research and Developments, vol. 40, no. 4, 706-715, 2017. DOI: 10.7508/ jmerd.2017.04.018.

10. Gievskij, A.M., Orobinskij, V.I., Gulevskij, V.A., Chernyshov, A.V. (2017). The use of a finite-volume method for solving hydrodynamic equations for substantiating individual parameters of a pneumatic system of grain cleaning machines,.Bulletin of Agrarian Science, vol. 5, no. 68, 65-73.

11. Tarasenko, A.P. (2012). Improving the means of mechanization to obtain high-quality grain. Bulletin of the Voronezh State Agrarian University, vol. 3, no. 34, 109-115.

12. Saitov, V.E. (2008). Regulation of air speed in the pneumatic system of grain cleaning machines. Tractors and agricultural machinery, vol. 3, 38-39.

13. Badretdinov, I.D., Mudarisov, S.G. (2017). Experimental substantiation of the two-phase air-grain pile parameters for simulating the operation of the pneumatic system of a grain cleaning machine. Bulletin of the Bashkir State Agrarian University, vol. 1, no. 41, 57-61.

14. Mudarisov, S.G., Badretdinov, I.D. (2013). Numerical implementation of a mathematical model of the technological process of the diametric fan in a rotating coordinate system News of the International Academy of Agrarian Education, vol. 17, 79-83.
15. Mudarisov, S.G., Rahimov, Z.S., Badretdinov, I.D., Akbatyrov, A.V., Farhutdinov, I.M. (2009). Modernization of technological lines of grain processing, taking into account economic conditions. In the collection: Scientific support for the sustainable functioning and development of the AIC materials of the All-Russian scientific-practical conference with international participation (in the framework of the XIX International specialized exhibition "AgroComplex-2009"), p. 122126.

16. Mudarisov, S.G., Badretdinov, I.D. (2010). The results of numerical simulation of the movement of airgrain mixture in the aspiration system of the grain cleaning machine. In the collection: Agrarian science and education at the present stage of development: experience, problems and ways of solving them, materials of the 2 nd International Scientific Practical Conference, p. 84-87.

17. Mudarisov, S.G., Badretdinov, I.D. (2013). Substantiation of the parameters of the diametrical fan based on a mathematical model of the process of its operation. In the collection: Integration of science and practice as a mechanism for the effective development of the agro-industrial complex Materials of the International scientific-practical conference in the framework of the XXIII International specialized exhibition "AgroComplex-2013", p. 363-367.

18. Vasilevskij, M.V., Romandin, V.I., Zykov, E.G. (2013). Transportation and sedimentation of particles in the processing technologies of dispersed materials: monograph. Tomskij politehnicheskij universitet, Publishing House of Tomsk Polytechnic University, p. 288.

19. Gabitov, I., Badretdinov I., Mudarisov, S., Khasanov, E., Lukhmanov, R., Nasyrov, R., Tuktarov, M., Atnagulov, D., Timeriashev, I. \& Pavlenko, V. (2018). Modeling the Process of Heap Separation in the Grain Harvester Cleaning System. Journal of Engineering and Applied Sciences, 13(8), 6517-6526.

20. Aipov, R.S., Yarullin, R.B., Gabitov, I.I., Mudarisov, S., Linenko, A., Farhshatov, M.N., Khasanov, E.R., Gabdrafikov, F.Z., Yukhin, G.P., Galiullin, R.R. Mechatronic system linear swing vibrating screen of a Grain Cleaner. Journal of Engineering and Applied Sciences, 13(8), 6473-6477.

Paper submitted: 27.08.2019.

Paper accepted: 28.10.2019.

This is an open access article distributed under the CC $B Y-N C-N D 4.0$ terms and conditions. 